\title{
Intensive training technique utilizing the dog's olfactory abilities to diagnose prostate cancer in men
}

\author{
Lucie Urbanová1, Vlasta Vyhnánková2 ${ }^{2}$ Sárka Krisová ${ }^{3}$, Dalibor Pacík², Alois Nečas ${ }^{1}$ \\ ${ }^{1}$ University of Veterinary and Pharmaceutical Sciences Brno, Faculty of Veterinary Medicine, Small Animal \\ Clinic, Department of Surgery and Orthopaedics, Brno, Czech Republic \\ ${ }^{2}$ University Hospital Brno, Department of Urology, Brno, Czech Republic \\ ${ }^{3}$ University of Veterinary and Pharmaceutical Sciences Brno, Faculty of Veterinary Medicine, Equine Clinic, \\ Brno, Czech Republic
}

Received May 20, 2014

Accepted October 22, 2014

\begin{abstract}
Carcinoma of the prostate is a commonly occurring malignant tumour in men and is a common cause of death. Early diagnosis and therapy is crucial for the successful treatment of this serious disease. It is therefore desirable to develop a sufficiently reliable, minimally invasive, and inexpensive method of diagnosing prostate cancer, which would usefully supplement the diagnostic techniques currently in common use (digital rectal examination, measuring the prostate-specific antigen level in serum, transrectal ultrasonography). This article describes in detail the methodology of a new technique for intensive training aimed at developing the dog's olfactory abilities to diagnose carcinoma of the prostate in men while the animal is still young. At the same time, the rate of success in establishing the diagnosis of prostate cancer in men using this method was evaluated based on the identification of urine samples from patients in whom the disease was histologically confirmed. The results of our study demonstrate that the diagnosis of prostate cancer in men using the olfactory abilities of a specially trained dog can be considered a reliable, non-invasive, and relatively inexpensive method of diagnosing carcinoma of the prostate.
\end{abstract}

Urology, tumour, prostate gland, auxiliary methods of examination

Carcinoma of the prostate is the most common non-cutaneous malignant tumour among men in a number of the world's developed countries and, after carcinoma of the lung, it is the most common solid tumour in the male population of the United States (Jemal et al. 2009). Despite the progressive development of diagnostic methods (Vyhnánková $2015)$ in the area of diagnosing cancer, this disease is still one of the major causes of death in humans. Early detection and prompt commencement of therapy are crucial for the successful treatment of carcinomas and an appropriate way of reducing the economic burden of treatment and the mortality of the disease (Sonoda et al. 2011). The basic diagnostic methods used to diagnose prostate cancer include digital rectal examination (DRE), measuring the prostate-specific antigen (PSA) level in serum, and transrectal ultrasonography (TRUS) (Gerber and Chodak 1991). When patients are making decisions about undergoing preventative or early examination, the degree to which the procedure carried out is invasive and painful is quite important. It is therefore desirable to develop a method of diagnosing prostate cancer which is sufficiently reliable, but at the same time minimally invasive and not too expensive.

In our study we focused on the development of diagnostics for prostate cancer in men from urine samples using the olfactory abilities of the dog. The aim of the study was to introduce a new technique for the intensive development of the dog's olfactory abilities to diagnose carcinoma of the prostate in men while the animal is young; to evaluate the success rate in establishing the diagnosis of prostate cancer in men on the basis of indicating urine

Address for correspondence:

Lucie Urbanová

Department of Surgery and Orthopaedics

Small Animal Clinic, Faculty of Veterinary Medicine

University of Veterinary and Pharmaceutical Sciences Brno, Czech Republic

Phone: +420606638088

E-mail: lucieurbanova@email.cz

http://actavet.vfu.cz/ 
samples from patients with a histologically confirmed prostate carcinoma; and to verify the reliability of this non-invasive method of diagnosing prostate cancer.

\section{Materials and Methods}

Sampling

Urine samples were collected at the Urological Clinic of the University Hospital in Brno. Patients have been compiled and published in the thesis of MUDr. Vlasta Vyhnánková (Vyhnánková 2015). Urine was obtained by spontaneous micturition. Positive samples came from patients with a histologically confirmed carcinoma of the prostate. The set of negative patients consisted of urine samples from urological patients with a negative histological report for the prostate. No urine samples from women were included in the study (not even as negative samples).

After collection, the urine was stored in disposable test tubes and, after being transported to the Clinic of Dog and Cat Diseases at the Veterinary and Pharmaceutical University in Brno, the samples were stored in freezing boxes at a temperature of $-20{ }^{\circ} \mathrm{C}$ until required. Before the samples were presented to the dog, the urine was slowly thawed and brought to room temperature.

The dog and its training

For the purposes of this study, a German Shepherd bitch named Agáta Jankari, born on May 1, 2012, was used. She began a special training programme at seven months of age. Prior to that, she had undergone basic obedience training (Jansen et al. 2011) and training in scent work (Jansen et al. 2011). The actual training of the dog at a young age utilizing its olfactory abilities to diagnose prostate cancer in men was based on the method of positive reinforcement using a clicker (Pry or 2006; Egtvedt and Køste 2012). The method of positive reinforcement consists of marking and rewarding desired behaviour. Correct behaviour was indicated using a clicker and immediately rewarded using a treat or a game with a toy.

The training area and samples

The training took place in a room designated for that purpose with a floor covered with marmoleum which was washed with a disinfectant solution every day. In the first stage, the samples along with the test tube were placed in a container of sand covered with gauze; later they were placed in plastic beakers of a volume of $30 \mathrm{ml}$ with a perforated lid. The beakers with the samples were fixed to the floor using an adhesive substance to prevent them from being knocked over.

The development of the dog's olfactory abilities to diagnose prostate cancer in men

The training of the dog which led to the utilization and development of its olfactory abilities to diagnose prostate cancer in men took place $\times 4-5$ per week for a period of 11 months. In the course of a day, 1-2 training sessions were carried out, during which the dog was dispatched $\times 3-6$ to check and evaluate one sample, later up to three samples ( 1 positive, 2 negative). On the other days, the training was aimed to improve physical condition and the development of olfactory abilities by working on the scent trail of the dog handler.

The actual training of the dog to diagnose prostate cancer was carried out as follows. The dog was first familiarized with the scent of a positive urine sample. Only one positive sample was placed in the centre of the training area in such a way as to allow the dog direct contact with the sample but at the same time to prevent it from potentially ingesting it. Initially, any kind of interest in the sample shown by the dog (approaching it, sniffing it, contact with the nose) was marked with a click and immediately rewarded with a treat or a game. In the next stage, the criteria for desired behaviour were raised by only marking "lying down by the sample" and placing the nose (Plate IV, Fig. 1) on the container with the sample. After consolidation of the desired behaviour with the container holding the positive sample, an identical container, this time with an empty test tube, was added to the training area. In the event that this container was indicated, this behaviour was not marked or rewarded and the dog was again invited to identify the correct sample. As soon as erroneous identification of the incorrect container had been eliminated, the test tube was filled with water and the exercise continued. In this stage there were almost no instances of erroneous identification. A second container with a test tube filled with water was therefore introduced. A further raising of the criteria consisted of exchanging the water in one of the test tubes for a negative urine sample. After several training sessions, the water in the second test tube was also exchanged for a negative urine sample.

Because of the risk of the container with the test tube being contaminated by the urine sample in the event that it was knocked over, which could lead to the dog becoming confused, the containers with the test tubes were replaced by beakers of a volume of $30 \mathrm{ml}$ with a perforated lid, into which the urine sample was poured directly.

In the event of contamination of the training area by a urine sample, the floor was immediately washed. The test containers were positioned on the floor in various ways depending on the stage of training.

The positioning of samples

In the early stages of training, a single positive sample was placed in the centre of the training area by the dog handler. After consolidation of the desired behaviour with the sample, the container with the positive sample was 
placed in various positions around the training room and the dog was sent towards it from various directions using the command "OK". When the other two containers were added (with an empty test tube, with water, with negative samples), they were positioned in a line of three containers next to each other, or behind each other, or in a triangle, and the dog was sent to identify the correct (positive) sample, still from various directions. In the course of a single training session, the samples were moved about in such a way that the dog could not observe this process. In the later stages of training, the samples were not positioned by the dog handler but by another person.

Evaluation of the dog's work

The actual testing of the reliability of diagnosing prostate cancer by making use of the dog's olfactory abilities with the identification of positive urine samples from patients with this disease (conclusively established by histology) was carried out after 11 months of special training, at which time the dog was 1.5 years old. Included in the testing were 70 samples, of which 45 were positive (urine from men with prostate cancer) and 25 were negative (urine from men without prostate cancer). Each time it was dispatched, 3 samples (always 1 positive and 2 negative) were presented to the dog. Lying down by the sample was regarded as positive identification, while checking the sample using smell then leaving it and moving on to another sample was regarded as negative identification (Plate IV, Fig. 2).

\section{Results}

The frequency with which our specially trained dog correctly identified positive urine samples from patients with histologically confirmed carcinoma of the prostate is shown in Table 1 . The sensitivity of identifying urine samples from patients with histologically confirmed prostate cancer using the olfactory abilities of the specially trained dog in our study was $93.5 \%$; the specificity of this diagnostic method was $91.6 \%$.

Table 1 . The frequency with which the specially trained dog identified positive and negative urine samples from patients with histologically confirmed prostate cancer (Vyhnánková in press).

\begin{tabular}{lccc}
\hline Identification by the dog & $\begin{array}{c}\text { Urine sample from } \\
\text { a patient with prostate cancer (n) }\end{array}$ & Negative urine sample (n) & No. of samples (n) \\
\hline Positive & 43 & 3 & 46 \\
Negative & 2 & 22 & 24 \\
Total & 45 & 25 & 70 \\
\hline
\end{tabular}

\section{Discussion}

The earliest reports on the use of dogs as "chemical detectors" date back to a time 12,000 years ago (Furton and Myers 2001). Dogs are accurate and reliable biosensors, which makes them useful detection technology (Furton and Myers 2001). Sniffer dogs have been used by police forces and civilian services worldwide as operational tools for more than 100 years (Lesniak et al. 2008). Their olfactory abilities are used to detect a wide range of scents (Lesniak et al. 2008; Hall et al. 2013), e.g. explosives (Goldblatt et al. 2009; Ada mkiewicz et al. 2013), narcotics (Adamkiewicz et al. 2013), tortoises (Cablk et al. 2008), cows in oestrus (Hawk et al. 1984; Fischer-Tenhagen et al. 2011), and to find lost people or bodies; dogs are used to identify exhibits in criminology (Lesniak et al. 2008). Thanks to the extraordinary sensitivity of the dog's sense of smell, a tiny amount of odorous substance is often enough to identify the relevant scent (Williams and Johnston 2002; Hepper and Wells 2005; Walker et al. 2006). This ability, together with the willingness that dogs exhibit to work with people and the relative ease with which they can be trained, is crucial for the use of dogs as "olfactory detectors" (Lesniak et al. 2008). At the same time, the results of the study can be affected by, for example, the choice of the dog breed, due to the polymorphism of the scent receptors, which contribute to a large degree to the olfactory abilities of dogs (Lesniak et al 2008). 
Studies have been published describing the more or less accidental discovery of skin melanomas by pet dogs (Williams and Pembroke 1989; Church and Williams 2001). Subsequently, some authors examined the diagnosis of tumours of the bladder (Willis et al. 2004), lungs and breast (McCulloch et al. 2006), ovaries (Horvath et al. 2008), colorectal carcinoma (Sonoda et al. 2011), and prostate cancer (Cornu et al. 2011). Our study also looks at the use of the dog's olfactory abilities in the sense of its ability to distinguish between urine from patients with prostate cancer and urine from patients free of the disease, with the use of a specific technique for intensively training the animal, with the aim to consolidate and develop this innate ability of the dog.

The advantage of prior obedience training and practice of scent work with the animal used in our study was that the dog was already familiar with the basic principles of training and rewards and was accustomed to working with the dog handler. Its previous experience of indicating by lying down beside objects on the track greatly simplified the process, because the dog very quickly offered precisely this desired behaviour with positive urine samples.

We were forced to change the method of presenting the samples for inspection (from test tubes placed in a container of sand to beakers fixed to the floor) due to the fact that, while hastily checking the sample, the dog sometimes knocked the container over, spilling the sample and contaminating the sand and container, which subsequently led to incorrect identification of the samples presented. This problem was eliminated by switching to samples in beakers.

The first test of the success rate of the training in distinguishing between urine from persons with prostate cancer and urine from persons without cancer was conducted after 11 months of training, when the dog was 1.5 years old. In a study by Cornu et al. (2011) the authors describe training a $\operatorname{dog} \times 5$ a week for a period of 16 months before the authors performed the first test to verify the dog's ability to identify positive and negative samples. Cornu et al. (2011) do not state the age of the Belgian Shepherd in their study, but the time, intensity and training method in both studies are comparable. The results obtained in terms of sensitivity (our study 93.5\%, Cornu et al. (2011) 91\%) and specificity (our study 91.6\%, Cornu et al. (2011) 91\%) are also similar.

The advantage of using such a young dog for the training is that it is not encumbered with undesirable habits arising from other trainings with different aims and, in addition, at that age it can be motivated very well during training (Stemmerová 2012). Given the very young age of the dog used in our study and the occasional inattentiveness and restlessness while working which were associated with it, improvement in the accuracy and reliability of distinguishing and identifying samples can be expected in future.

During the training, deterioration in the bitch's concentration and work was recorded when she was in heat. This undesirable situation could be eliminated by choosing an individual of the opposite sex (a male dog), although it is also necessary to take into account the fact that male dogs can, on the other hand, be significantly distracted when bitches in the vicinity are in heat (Egtvedt and Køste 2012). In future, the factor of deterioration in the bitch's concentration while in heat will be eliminated by performing ovariectomy.

The choice of dog which is not merely to be a "pet" but is to be a useful assistant in particular work is not easy and, for example, selection of dogs for use by the Czech Army is carried out by an expert committee (Nový 1995). In order to successfully employ working dogs in specific training it is necessary to determine the predominant reactions (of orientation, defence, feeding, passive defence), the dog's degree of excitability, the condition of its sense organs, and the exterior (Nový 1995). In the first phase of selection, the dog's willingness to train is assessed and it is not until the second phase that its aptitude for a particular type of service is established (Ryneš 1997). In our study we used a bitch which had already exhibited inclinations towards scent work and a strong willingness to 
train as a puppy. However, it is possible that not every dog of a working breed will have the necessary capabilities for this specific training.

Based on the established relatively high sensitivity $(93.5 \%)$ and specificity $(91.6 \%)$ of diagnosing prostate cancer using the olfactory abilities of a dog trained by a specific intensive technique practising and developing these innate faculties of the animal at an early age, it can be stated that the described method of identifying cancer-specific substances in samples of urine may become a newly employed and, for clinical practice, beneficial technique which could make the diagnosis of this deadly disease faster and more accurate in future. The results of our study demonstrate that diagnosing prostate cancer in men using the olfactory abilities of a specially trained dog can be regarded as a relatively reliable, non-invasive, and comparatively inexpensive method. In future this method may usefully supplement the existing range of diagnostic methods commonly used to detect carcinoma of the prostate.

\section{Acknowledgements}

The work was funded by contract research (Framework Agreement on Cooperation between UVPS Brno and UH Brno, modified by Sub-Agreements No.1 and 2 on the Framework Agreement on Cooperation concluded 25. 2. 2013). Our thanks go to MVDr. Petra Fedorová, MVDr. Daniela Čapková and the veterinary technicians of the Clinic of Dog and Cat Diseases at FVM UVPS Brno, who contributed to the care of the dog during its training.

\section{References}

Adamkiewicz E, Jezierski T, Walczak M, Gorecka-Bruzda A, Sobczynska M, Prokopczyk M, Ensminger J 2013: Traits of drug and explosives detection in dogs of two breeds as evaluated by their handlers and trainers. Anim Sci Pap Rep 31: 205-217

Cablk ME, Sagebiel JC, Heaton JS, Valentin C 2008: Olfaction-based detection distance: A quantitative analysis of how far away dogs recognize tortoise odor and follow it to source. Sensors 8: 2208-2222

Church J, Williams H 2001: Another sniffer dog for the clinic? Lancet 358: 930

Cornu JN, Cancel-Tassin G, Ondet V, Girardet C, Cussenot O 2011: Olfactory detection of prostate cancer by dogs sniffing urine: a step forward in early diagnosis. Eur Urol 59: 197-201

Egtvedt M, Køste C 2012: Clicker training (in Czech). Nakladatelství PLOT, Praha, 240 p.

Fischer-Tenhagen C, Wetterholm L, Tenhagen BA, Heuwieser W 2011: Training dogs on a scent platform for oestrus detection in cows. Appl Anim Behav Sci 131: 63-70

Furton KG, Myers LJ 2001: The scientific foundation and efficacy of the use of canines as chemical detectors for explosives. Talanta 54: 487-500

Gerber GS, Chodak GW 1991: Routine screening for cancer of the prostate. J Natl Cancer Inst 83: 329-335

Goldblatt A, Gazit I, Terkel J 2009: Olfaction and explosives detector dogs. In: Helton W (Ed.): Canine ergonomics: The science of working dogs. Boca Raton, FL: CRC Press, pp. 135-175

Hall NJ, David W, Smith DW, Wynne CDL 2013: Training domestic dogs (Canis lupus familiaris) on a novel discrete trials odor-detection task. Learn Motiv 44: 218-228

Hawk HW, Conley HH, Kiddy CA 1984: Estrus-related odors in milk detected by trained dogs. J Dairy Sci 67: 392-397

Hepper PG, Wells DL 2005: How many footsteps do dogs need to determine the direction of an odour trail? Chem Senses 30: 291-298

Horvath G, Jarverud GA, Jarverud S, Horváth I 2008: Human ovarian carcinomas detected by specific odor. Integr Cancer Ther 7: 76-80

Jemal A, Siegel R, Ward E, Hao Y, Xu J, Thun MJ 2009: Cancer statistics. CA Cancer J Clin 59: 225-249

Jansen F, Diegel G, Schaepermeier W, Scherkl E, Walhlstroem P, Van den Bosch F, Markschlaeger R 2011: Regulations for the international utility dog trials and the international tracking dog trial of the FCI. Available at: http://www.fci.be. Accessed September 6, 2014.

Lesniak A, Walczak M, Jezierski T, Sacharczuk M, Gawkowski M, Jaszczak K 2008: Canine olfactory receptor gene polymorphism and its relation to odor detection performance by sniffer dogs. J Hered 99: 518-527

McCulloch M, Jezierski T, Broffman M, Hubbard A, Turner K, Janecki T 2006: Diagnostic accuracy of canine scent detection in early- and late-stage lung and breast cancers. Integr Cancer Ther 5: 30-39

Nový K 1995: Methods for training service dogs. Dog breeding manual (in Czech). Naše vojsko, Praha, 159 p.

Pryor K 2006: Clicker training, What is clicker training. Available at: http://www.clickertraining.com/whatis. Accessed September 5, 2014.

Ryneš M 1997: Air scenting dog works in sport cynology (in Czech). Dona, České Budějovice, 69 p.

Sonoda H, Kohnoe S, Yamazato T, Satoh Y, Morizono G, Shikata K, Morita M, Watanabe A, Morita M, Kakeji 
Y, Inoue F, Maehara Y 2011: Colorectal cancer screening with odour material by canine scent detection. Gut 60: $814-819$

Stemmerová L 2012: Obedience (in Czech). Nakladatelství PLOT, Praha, 129 p.

Vyhnánková V 2015: Possibilities of prostate cancer prediction (in Czech). Dissertation work, Brno: University Hospital Brno, Department of Urology, Brno, Czech Republic, 92 p.

Walker DB, Walker JC, Cavnar PJ, Taylor JL, Pickel DH, Hall SB, Suarez JC 2006: Naturalistic quantification of canine olfactory sensitivity. Appl Anim Behav Sci 97: 241-254

Williams M, Johnston JM 2002: Training and maintaining the performance of dogs (Canis familiaris) on an increasing number of odor discriminations in a controlled setting. Appl Anim Behav Sci 78: 55-65

Williams H, Pembroke A 1989: Sniffer dogs in the melanoma clinic? Lancet 1: 734

Willis CM, Church SM, Guest CM, Cook WA, McCarthy N, Bransbury AJ, Church MRT, Church JCT 2004: Olfactory detection of human bladder cancer by dogs: proof of principle study. BMJ 329: 712 
Plate IV

Urbanová L. et al.: Intensive training ... pp. 77-82

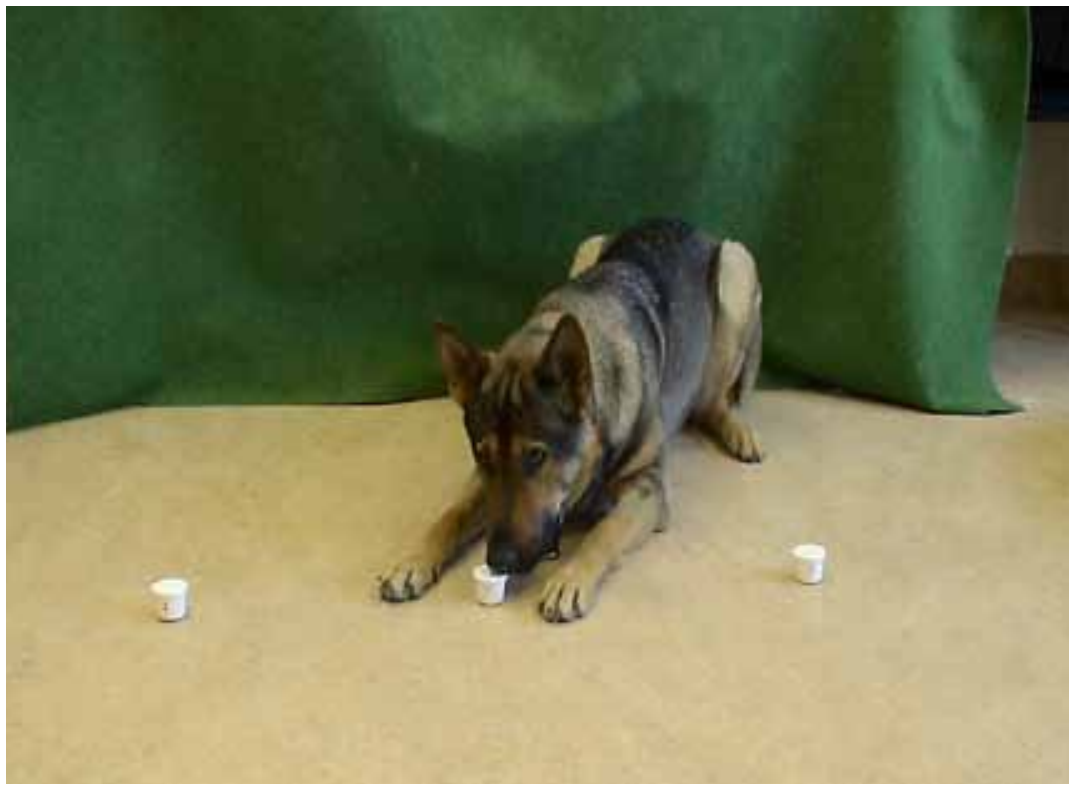

Fig. 1. Dog lying by the positive sample and placing its nose on the container holding the test tube with the urine sample

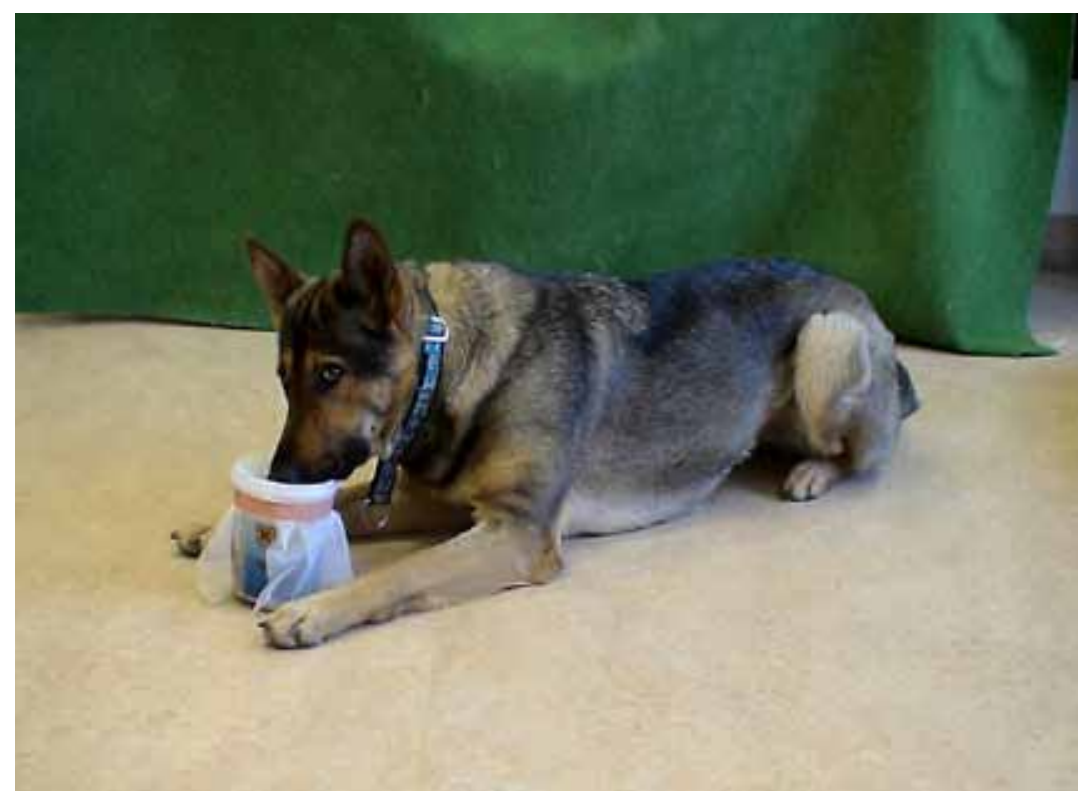

Fig. 2. Dog indicating cancer in the positive urine sample 